\title{
Can primary optimal cytoreduction be predicted in advanced epithelial ovarian cancer preoperatively?
}

Azam-Sadat Mousavi, Marjan Moradi Mazhari, Mitra Modares Guilani, Fatemeh Ghaemmaghami, Nadereh Behtash, Setareh Akhavan

\begin{abstract}
Introduction: Prediction of optimal cytoreduction in patients with advanced epithelial ovarian caner preoperatively.

Methods: Patients with advanced epithelial ovarian cancer who underwent surgery for the first time from Jan. to June 2008 at gynecologic oncology ward of TUMS (Tehran University of Medical Sciences) were eligible for this study. The possibility of predicting primary optimal cytoreduction considering multiple variables was evaluated. Variables were peritoneal carcinomatosis, serum CA125, ascites, pleural effusion, physical status and imaging findings.

Univariate comparisons of patients underwent suboptimal cytoreduction carried out using Fisher's exact test for each of the potential predictors. The wilcoxon rank sum test was used to compare variables between patients with optimal versus suboptimal cytoreduction.
\end{abstract}

Results: 41 patients met study inclusion criteria. Statistically significant association was noted between peritoneal carcinomatosis and suboptimal cytoreduction. There were no statistically significant differences between physical status, pleural effusion, imaging findings, serum CA125 and ascites of individuals with optimal cytoreduction compared to those with suboptimal cytoreduction.

Conclusions: Because of small populations in our study the results are not reproducible in alternate populations. Only the patient who is most unlikely to undergo optimal cytoreduction should be offered neoadjuvant chemotherapy, unless her medical condition renders her unsuitable for primary surgery.

\section{Introduction}

Ovarian cancer is the leading cause of morbidity and mortality among the gynecologic cancers [1]. Epithelial ovarian cancers consist $90 \%$ of all ovarian cancers [2]. Stage 3 and 4 (as defined by the staging classification of the International Federation of Gynecology and Obstetrics) consist about $2 / 3$ of cases of epithelial ovarian cancer in the time of diagnosis [1-3]. Advanced epithelial ovarian cancers are currently managed with laparotomy + hysterectomy + bilateral salpingooophorectomy + omentectomy + resection of tumoral mass as completely as possible and then platinum based chemotherapy.

\footnotetext{
* Correspondence: moradim2009@yahoo.co.uk

Department of Gynecology Oncology, vali-e-asr hospital, Tehran University of Medical Sciences, Keshavarz Blvd, Tehran, 1419733141, Iran
}

Maximal diameter of residual tumor after surgery and before starting chemotherapy is an important determinant of prognosis, this has been shown by all studies about advanced epithelial ovarian cancer [4-6].The definition of optimal surgery has been evolved and it is currently defined as residual tumor less than $1 \mathrm{~cm} \mathrm{[5].}$ Optimal surgery is associated with both a more favorable response to chemotherapy and prolonged survival [7]. The study of GOG has shown that only if the residual tumor is optimal (less than $1 \mathrm{~cm}$ ) the survival will prolong[5].The success rate of primary optimal cytoreduction for advanced epithelial ovarian cancers is highly variable, depending upon individual and institutional treatment philosophies and experiences. In centers with a particular interest and experience in cytoreductive

C Biomed Central

(C) 2010 Mousavi et al; licensee BioMed Central Ltd. This is an Open Access article distributed under the terms of the Creative Commons Attribution License (http://creativecommons.org/licenses/by/2.0), which permits unrestricted use, distribution, and reproduction in any medium, provided the original work is properly cited. 
surgery, rates of optimal resection are reported in 60$90 \%$ of cases $[8,9]$.

It is not possible to do primary optimal debulking for all patients, in these cases primary surgery not only dose not have any benefit but also causes morbidity [10]. The 30-day mortality rate for women undergoing primary surgery for ovarian cancer ranged from 1-3\% [11]. Moreover, not performing primary surgery in all cases result in omitting the chance of improved survival for some patients.

Primary debulking in patients with advanced epithelial ovarian cancer has been compared with chemotherapy and interval debulking in different studies. Equal survival has been reported in patients undergoing primary surgery compared to patients undergoing debulking surgery after taking chemotherapy by Onnes et al. [12]. They have reported that optimal debulking was achieved in $42 \%$ of patients who treated primarily with chemotherapy in comparison with $29 \%$ of patients who underwent primary surgery.

In 1999, Shwartz et al. demonstrated that women who underwent cytoreductive surgery after induction chemotherapy had statistically improved overall survival compared to women who did not undergo surgery[13]. One randomized prospective study demonstrated that women undergoing interval cytoreductive surgery had improved both overall and progression-free survival[11]. It is supposed that less invasive surgery is required for optimal cytoreduction after neoadjuvant chemotherapy. Ansquer et al. in their study have noticed that the morbidity of cytoreductive surgery after neoadjuvant chemotherapy is less than primary debulking [14]. It is noticeable that by performing primary cytoreductive surgery, surgical staging will be done, sensitivity to chemotherapy will increase, risk of mutation will reduce and general status of patient will improve. Considering these, nowadays primary surgery is the preferred management for patients with advanced epithelial ovarian cancer. In America $95 \%$ of patients with advanced epithelial ovarian cancer are treated with primary surgery [15].

Regarding that residual tumor is more than $1 \mathrm{~cm}$ in many patients underwent primary surgiery, considering another method in this group of patients seems necessary. Although neoadjuvant chemotherapy and interval cytoreduction sounds to be good management but its indications have not yet determined.

A critical point in order to define indications of neoadjuvant chemotherapy for advanced ovarian cancer is determination of uniform selection criteria that can consistently identify patients with surgically unresectable disease without depriving others from potential advantage associated with an optimal primary resection.
Several studies have been done for determining markers which can reliably predict optimal resectability [16-18]. CT-Scan findings [17], serum CA-125[18], pleural effusion [19] and ascites $[19,20]$ have been assessed in different studies in order to predict optimal debulking preoperatively but up to now the predictive performance of clinical parameters(e.g ascites), serum CA125 values and imaging criteria have not demonstrated sufficient accuracy to achieve widespread applicability[13]. Thus further investigation concerning patient selection seems warranted. Therefore, we planed the prospective study for assessing the probability of predicting preoperatively optimal cytoreduction with considering combination of variants (abdominal and pelvic CT-scan or MRI findings - presurgical serum CA_125 level- pleural effusionascites and physical status) in patients with advanced epithelial ovarian cancer who were admitted at gynecology oncology ward of the Tehran Vali-e-asr hospital and undergoing primary surgery from Jan. to June 2008.

\section{Patients and Methods}

Approval to conduct this study was obtained from research organization of gynecologic oncology department of Tehran University of Medical Sciences(TUMS). Patients with stage 3 and stage 4 epithelial ovarian cancer underwent primary surgery between Jan. to June 2008 at gynecologic oncology ward of Vali-e-Asr hospital of TUMS were eligible for entering the study.

The possibility of predicting primary optimal cytoreduction considering multiple variables was assessed in this group. Variables were peritoneal carcinomatosis, serum CA125 level, ascites, pleural effusion, physical status and imaging findings.

All surgeries were performed by gynecologic oncologists of TUMS. Optimal cytoreduction was defined as $\leq$ $1 \mathrm{~cm}$ residual disease. All imagings were reported by the professors of radiology of TUMS. Considered imaging parameters included: omental extention, liver involvement, peritoneal involvement and suprarenal adenopathy. Blood samples for measuring serum CA125 levels were taken at the morning.

Physical statusesof patients were defined according to physical status classification of the American society of anesthesiology. In addition we considered optimal and suboptimal cytoreduction. Residual tumor less than $1 \mathrm{~cm}$ after surgery was considered as optimal cytoreduction.

Univariate comparisons of the percentage of patients who underwent suboptimal cytoreduction carried out using Fisher's exact test for each of the potential predictors. The wilcoxon rank sum test was used to compare variables between patients with optimal versus suboptimal cytoreduction. 


\section{Results}

Forty one patients from patients who were admitted at Vali-e-Asr hospital of TUMS from Jan. to June 2008 met study inclusion criteria. Demographic and clinical data are described in table 1 . Seventy-three percent of patients had FIGO (international federation of gynecology and obstetrics staging system) stage 3 disease while $17 \%$ of patients had FIGO stage 4 disease. Forty-one percent were optimally cytoreduced to $\leq 1 \mathrm{~cm}$ residual disease at the time of primary surgery.

Peritoneal carcinomatosis and suboptimal cytoreduction had statistically significant assosciation. There were no statistically significant differences between physical status, pleural effusion, imaging findings, CA125 serum levels and ascites in patients with optimal cytoreduction compared to those who underwent suboptimal debulking.

Table 1 Clinical Data and Tumor Characteristic Study

\begin{tabular}{|c|c|c|}
\hline \multirow[t]{2}{*}{ Characteristic } & \multicolumn{2}{|c|}{ Patients } \\
\hline & No. & $\%$ \\
\hline \multicolumn{3}{|l|}{ Clinical status } \\
\hline 1 & 27 & 65.9 \\
\hline 2 & 13 & 31.7 \\
\hline \multicolumn{3}{|l|}{ Pleural effusion } \\
\hline Positive & 7 & 17 \\
\hline Negative & 34 & 82.9 \\
\hline \multicolumn{3}{|l|}{ Bowel resection } \\
\hline Positive & 1 & 2.4 \\
\hline Negative & 39 & 96.6 \\
\hline \multicolumn{3}{|c|}{ Intraperitoneal carcinomatosis } \\
\hline Positive & 22 & 53.6 \\
\hline Negative & 19 & 46.4 \\
\hline \multicolumn{3}{|l|}{ Imaging findings } \\
\hline \multicolumn{3}{|l|}{ Omental extension } \\
\hline Positive & 6 & 14.6 \\
\hline Negative & 34 & 85.4 \\
\hline \multicolumn{3}{|l|}{ Liver invlovement } \\
\hline Positive & 5 & 12.1 \\
\hline Negative & 36 & 87.9 \\
\hline \multicolumn{3}{|l|}{ Peritoneal involvement } \\
\hline Positive & 12 & 29.2 \\
\hline Negative & 29 & 70.8 \\
\hline \multicolumn{3}{|l|}{ Suprarenal adenopathy } \\
\hline Positive & 0 & 0 \\
\hline Negative & 41 & 100 \\
\hline \multicolumn{3}{|l|}{ CA-125 } \\
\hline$\leq 400$ & 11 & 27.5 \\
\hline$>400$ & 29 & 72.5 \\
\hline \multicolumn{3}{|l|}{ Ascitis } \\
\hline$\leq 1000$ & 22 & 53.6 \\
\hline$>1000$ & 19 & 46.4 \\
\hline
\end{tabular}

Table 2 presents the percentage of patients who underwent suboptimal and optimal debulking for each of 9 considered variables. Optimal debulking was performed for $44.4 \%$ of patients with physical status 1 (according to classification of American society of anesthesiologist (A.S.A)) and $55.6 \%$ of these patients undergoing suboptimal debulking. Patients with A.S.A class 2 suboptimally debulked in $76.9 \%$ of cases and optimlly debulked in $23.1 \%$.About $85 \%$ of patients have pleural effusion were suboptimally debulked while only $14.3 \%$ of these patients were optimally debulked. Patients who did not have pleural effusion undergoing optimal cytoreduction in $41.2 \%$ and suboptimal cytoreduction in $58.8 \%$.We had only one case of bowel resection which resulted in optimal debulking. Suboptimal debulking was performed in $84.2 \%$ of patients with peritoneal carcinomatosis, $50 \%$ with omental extention, $60 \%$ with liver involvement, $58.3 \%$ with peritoneal involvement,63.3\%with CA125 $\leq 400$ and $59.5 \%$ with ascites $\leq$ 1000 in comparison with optimal cytoreduction undergoing in $15.8 \%, 50 \%, 40 \%, 41.7 \%, 36.4 \%, 45.5 \%$ of these groups of patients respectively.

\section{Discussion}

Our current study identifies intraperitoneal carcinomatosis as being the only statistically significant predictor of suboptimal cytoreduction. Table 2 demonstrates $P$ value, positive predictive value and negative predictive value of each of the variables for predicting optimal and suboptimal debulking. There were no statistically significant relationship between considered variables and optimal or suboptimal cytoreduction except to intraperitoneal carcinomatosis.

There is no statistically significant difference between pleural effusions in individuals underwent optimal cytoreduction compared to those with suboptimal cytoreduction. It seems that low number of patients caused this result because the number of patients who were suboptimally cytoreduced is in confidence interval range of those who were optimally cytoreduced.The number of patients in our study is only 41 . Considering small sample size of the study, proofing these results demands larger randomized study. We used imaging findings as predictive predictors of suboptimal debulking according to previous studies which had mentioned these factors have predictive value.

To date, the predictive performance of clinical parameters, serum CA-125 threshold values, and radiographic imaging criteria have not demonstrated sufficient accuracy to achieve widespread applicability [13,21-24].

The most common criteria cited as justification for abandoning an up-front attempt at surgical cytoreduction are ascites volume greater than $1000 \mathrm{ml}$, peritoneal carcinomatosis, parenchymal liver disease, splenic metastasis or omental extension to the spleen, porta 
Table 2 Univariate Analysis of Predictors of Suboptimal Cytoreduction

\begin{tabular}{|c|c|c|c|c|c|}
\hline \multirow[b]{3}{*}{ Predictor } & \multicolumn{5}{|c|}{ patients } \\
\hline & \multicolumn{2}{|c|}{ Optimal Cytoreduction } & \multicolumn{2}{|c|}{ Suboptimal Cytoreduction } & \multirow[b]{2}{*}{$\mathbf{P}$} \\
\hline & No. & percent & No. & percent & \\
\hline \multicolumn{6}{|l|}{ Clinical status } \\
\hline 1 & 12 & 44.4 & 15 & 55.6 & 1.91 \\
\hline 2 & 3 & 23.1 & 10 & 76.9 & \\
\hline \multicolumn{6}{|l|}{ Pleural effusion } \\
\hline Positive & 1 & 14.3 & 6 & 85.7 & .179 \\
\hline Negative & 14 & 41.2 & 20 & 58.8 & \\
\hline \multicolumn{6}{|l|}{ Peritoneal carcinomatosis } \\
\hline Positive & 3 & 15.8 & 16 & 84.2 & .01 \\
\hline Negative & 12 & 54.5 & 10 & 45.5 & \\
\hline \multicolumn{6}{|l|}{ Omental extension } \\
\hline Positive & 3 & 50 & 3 & 50 & .460 \\
\hline Negative & 12 & 34.3 & 23 & 65.7 & \\
\hline \multicolumn{6}{|l|}{ Liver involvement } \\
\hline Positive & 2 & 40 & 3 & 60 & .866 \\
\hline Negative & 13 & 36.1 & 23 & 63.9 & \\
\hline \multicolumn{6}{|l|}{ Peritoneal involvement } \\
\hline Positive & 5 & 41.7 & 7 & 58.3 & .664 \\
\hline Negative & 10 & 34.5 & 19 & 65.5 & \\
\hline \multicolumn{6}{|l|}{ Adenopathy } \\
\hline Positive & 0 & 0 & 0 & 0 & \\
\hline Negative & 15 & 36.6 & 26 & 63.4 & \\
\hline \multicolumn{6}{|l|}{ CA-125 } \\
\hline$\leq 400$ & 4 & 36.4 & 7 & 63.6 & .911 \\
\hline$>400$ & 10 & 34.5 & 19 & 65.5 & \\
\hline \multicolumn{6}{|l|}{ Ascitis } \\
\hline$\leq 1000$ & 10 & 45.5 & 12 & 54.5 & .205 \\
\hline$>1000$ & 5 & 26.3 & 14 & 73.7 & \\
\hline
\end{tabular}

hepatitis disease, and bulky disease involving the diaphragm[8] one of the earliest studies attempting to forecast the surgical outcome of patients with advanced stage ovarian cancer assessed the predictive value of these criteria in a series of 42 patients[15].In this sentinel study, Nelson et al reported a positive predictive value for a suboptimal surgical result of $67 \%$. Not to be overlooked, it is the fact that one out of every three patients thought to have unresectable tumor would have been left with optimal residual disease if offered primary surgery. More recently, Axtell et al. [25] reported data that highlight the difficulty in defining universally applicable selection criteria that reliably predict surgical outcome across institutions and surgeons.

One of the principle difficulties in development of any reliable predictive model of surgical outcome for patients with advanced ovarian cancer is the challenge of factors in the significant impact of each institute surgeons' philosophy, effort and ability to utilize advanced surgical techniques to achieve maximal cytoreduction, in order to omit this factor, in this study all surgeries were performed by gynecologic oncology professors of TUMS.

In summary, identification of risk factors for suboptimal cytoreduction in small populations such as ours is not reproducible in alternate populations. Until prospective randomized trials have demonstrated that neoadjuvant chemotherapy followed by interval cytoreduction is equivalent in terms of survival outcomes to primary optimal cytoreduction followed by chemotherapy, extreme caution should be used when applying preoperative predictors to decide between primary surgical exploration and neoadjuvant chemotherapy in the medically fit patient. Only the patient who is most unlikely to undergo optimal cytoreduction should be offered neoadjuvant chemotherapy, unless her medical condition renders her unsuitable for primary surgery. 


\section{Authors' contributions}

AM: supervised research project, carried out operations, supervised statistics. MMM: participated in operation as first aid, collect data, drafted the manuscript, and acted as corresponding author and did the revisions. MMG: carried out operations, she was head of the department. FG: carried out operations. NB: carried out operations. SA: participated in operation as first aid.

\section{Competing interests}

The authors declare that they have no competing interests.

Received: 15 November 2009 Accepted: 19 February 2010 Published: 19 February 2010

\section{References}

1. Landis SH, Murray T, Bolden S, Wingo PA: Cancer statistics, 1999. CA Cancer J Clin 1999, 49:8-31.

2. Scully RE, Young RH, Clement PB: Tumors of ovary, maldeveloped gonads, fallopian, tube, and broad ligament. Atlas of tumor pathology, fascicle 23 3rd series Washington, DC: Armed Forces Institute of pathology 1998, 1-168.

3. Jemal A, Murray T, Samuels A, Ghafoor A, Ward E, Thun MJ: Cancer statistics, 2003. CA Cancer J clin 2003, 53:5-26.

4. Hoskins WJ, Bundy BN, Thigpen JT, Omura GA: The influence of cytoreductive surgery on recurrence-free interval and survival in smallvolume stage3 epithelial ovarian cancer: a gynecologic oncology group study. Gynecol Oncol 1992, 47:159-66.

5. Hoskins WJ, McGurie WP, Brady MF, Homseley HD, Creaseman WT, Berman M, Ball H, Berek JS: The effect of diameter of largest residual disease on survival after primary cytoreductive surgery in patients with suboptimal residual epithelial ovarian carcinoma. Am J Obstet Gynecol 1994, 170:974-80.

6. Hoskins WJ: Epithelial ovarian carcinoma: principles of primary surgery. Gynecol Oncol 1994, 55:591-96.

7. Bristow BE, Tomacruz BS, Armstrong DK, Elmontz EL: Survival effect of maximal cytoreductive surgery for advanced ovarian carcinoma during the platinum era: a meta analysis. J Clin Oncol 2002, 20:1248-1259.

8. Vergote I, DeWever I, Tjalma W, Gramberen M, Decloedt J, Dam P: Neoadjuvant chemotherapy or primary debulking surgery in advanced ovarian carcinoma: a retrospective analysis of 258 patients. Gynecol Oncol 1998, 71:431-6.

9. Eisenkop SM, Friedman Rl, Wang HJ: Complete cytoreductive surgery is feasible and maximizes survival in patients with advanced epithelial ovarian cancer: a prospective studt. Gynecol Oncol 1998, 69:103-8.

10. Heintz APM, Hacker NF, Berek JS, Rose TP, Munoz AK, Lagasse LD: Cytoreductive surgery in ovarian carcinoma: feasibility and morbidity. Obstet Gynecol 1986, 67:783-8.

11. Burg Van der ME, van Lent M, Buyse M, Kobierska A, colombo N, Favalli G, Lacave AJ, Nardi M, Renard J, Pecorelli S: The effect of debulking surgery after induction chemotherapy on the prognosis in advanced epithelial ovarian cancer. Gynecological Cancer Cooperative Group of the European Organization for Research and Treatment of Cancer. N Engl J Med 1995, 332:629-634.

12. Onnis A, Marchetti M, Padovan P, Castellan L: Neoadjuvant chemotherapy in advanced ovarian cancer. Eur J Gynaecol Oncol 1996, 17:393-6.

13. Schwartz PE, Rutherford TJ, Chambers JT, Kohorn El, Thiel RP: Neoadjuvant chemotherapy for advanced ovarian cancer: long-term survival. Gynecol Oncol 1999, 72:93-99.

14. Ansquer $Y$, Leblanc E, Clough $K$, Morice $P$, Dauplat J, Mathevet $P$, Lhomme C, Scherer C, Tigaud JD, Benchaib M, Fourme E, Castaigene D, Querleu D, Dargent D: Neoadjuvant chemotherapy for unresectable ovarian carcinoma. A French multicenter study. Cancer 2001, 91:2329-34.

15. Eisenkop SM, Spirtos NM: What are the current surgical objectives, strategies, and technical capabilities of gynecologic oncologist treating advanced epithelial ovarian cancer?. Gynecol Oncol 2001, 82:489-97.

16. Nelson BE, Rosenfeld AT, Schwardz PE: Preoperative abdominopelvic computed tomographic prediction of optimal cytoreduction in epithelial ovarian carcinoma. J Clin Oncol 1993, 11:166-72.

17. Barlow M, Pazybylkski M, Schilder Jm: The utility of presurgical CA125 to predict optimal tumor cytoreduction of epithelial ovarian cancer. Int J Gynecol Cancer 2006, 16:495-500.
18. Memarzadeh, Lee SB, Berek JS, Farias-Eisner R: Ca-125 levels are a weak predictor of optimally cytoreductive surgery in patients with advance epithelial ovarian cancer. Int I Gynecol Cancer 2003, 13:120-124.

19. Martinez-Said H, Rincon DG, Montes De Oca MM, Ruiz GC, Ponce JLA, Lopez-Graniel CM: Predictive factors for irresectibility in advanced ovarian cancer. Int J Gynecol Cancer 2004, 14:423-30

20. Eltabbakh GH, Mount SL, Beatty B, Simmons-Arnold L, Cooper K, Morgan A: Factors associated with cytoreducibility among women with ovarian carcinoma. Gynecol Oncol 2004, 95:377-83.

21. Chan YM, Ng TY, Ngan HYS, Wong LC: Quality of life in women treated with neoadjuvant chemotherapy for advanced ovarian cancer: a prospective longitudinal study. Gynecol Oncol 2002, 88:9-16.

22. Fanfani F, Ferrandina G, Corrado G, Fagotti A, Zakut Hv, Mancuso S, Scambia G: Impact of interval debulking surgery on clinical outcome in primary unresectable FIGO stage3c ovarian cancer patients. Oncology 2003, 65:316-22.

23. Morice P, Dubernard G, Rey A, Atallah D, Pautier P, Pomel C, Lhommé C, Duvillard P, Castaigne D: Results of interval debulking surgery compared with primary debulking surgery in advanced stage epithelial ovarian cancer. J Am Coll Surg 2003, 197:955-63.

24. Lu KF, Kose MF, Boran N, Caliskan E, Tulunay G: Neoadjuvant chemotherapy or primary surgery in advanced epithelial ovarian carcinoma. Int J Gynecol Cancer 2001, 11:466-70.

25. Axtell AE, Lee MH, Bristow RE, Dowdy SC, Cliby WA, Raman S, Weaver JP, Gabbay M, Ngo M, Lentz S, Cass I, Li AJ, Karlan BY, Holschneider CH: Multiinstitutional reciprocal validation study of computed tomography predictors of suboptimal primary cytoreduction in patients with advanced ovarian cancer. J Clin Oncol 2007, 25(4):384-9.

doi:10.1186/1477-7819-8-11

Cite this article as: Mousavi et al: Can primary optimal cytoreduction be predicted in advanced epithelial ovarian cancer preoperatively?. World Journal of Surgical Oncology 2010 8:11.

\section{Submit your next manuscript to BioMed Central and take full advantage of:}

- Convenient online submission

- Thorough peer review

- No space constraints or color figure charges

- Immediate publication on acceptance

- Inclusion in PubMed, CAS, Scopus and Google Scholar

- Research which is freely available for redistribution
C Biomed Central 